\title{
Spaces of Joint Inquiry Through Visual Facilitation and Representations in Higher Education: An Exploratory case study
}

\author{
Heidi Hautopp and Stine Ejsing-Duun \\ IT, Learning and Design Lab, Aalborg University, Copenhagen, Denmark \\ hhau@hum.aau.dk \\ sed@hum.aau.dk \\ DOI: 10.34190/JEL.18.5.001
}

\begin{abstract}
This study investigates how the use of visual facilitation and representations, e.g. visualisations and video productions, combined with peer-feedback sessions can create exploratory approaches to game design in online teaching. The article analyses an iterative game development process in an online learning context. The empirical data is primarily based on an explorative case study of "Games for change"; a course held in 2018 in which master students from the international Nordic Visual Studies and Art Education (NoVA) design games that address issues in society. Throughout the course, the students from universities in Finland, Sweden and Denmark engaged in a cross-cultural collaboration across campuses. The purpose of the study was to explore how to establish an online space for joint design inquiry in the context of 'games for change' across time and space as well as cultural and professional barriers. The data used for analysis includes teaching observations, videos of play sessions, photos and visual representations, students' reflection papers and students' written and oral evaluations after completion of the course. The analysis is based on different problem-based learning (PBL) activities; lectures, video instructions, presentation- and feedback sessions, reflexive exercises and students' self-directed design and learning processes in groups. As part of the game course, teachers presented game theory and exercises through videos and visualisations to support the students' iterative game design processes. The analysis of the PBL activities shows that teachers' video instructions relating theoretical game concepts to the students' actual group work supported the introduction to the game field as well as their design processes. The balance between the value of video instructions with specific feedback and teachers' time for preparation is a relevant issue for further exploration in online teaching. Moreover, findings show that the students' visualisations and video productions exemplifying game situations created a visible reference point for further discussions in feedback sessions across campuses, which guided game development. Thus, the combination of inquiry approaches, critical game theory and design processes combined with students' visualisations and video productions provides interesting connections for bridging gaps between cultures and professions, e.g. in art and games. By the rich and visual descriptions of PBL activities, student work and reflective evaluations, the exploratory case study can function as inspiration for applying similar approaches to new local contexts in higher education.
\end{abstract}

Keywords: visual facilitation, visualisations, online learning, students as designers, design as inquiry, higher education

\section{Introduction}

This paper revolves around an exploratory case study on the use of visual facilitation and visual representations, e.g. visualisations and video productions, in online game-based learning at universities, specifically for the master program Nordic Visual Studies and Art Education (NoVA). The purpose of the study was to explore how to establish an online space for joint design inquiry in the context of 'games for change' across time and space as well as cultural and professional barriers. In a previous research and development project, we have explored the students' design and learning experiences when adopting a pragmatic inquiry approach (Dewey, 1938) in the process of developing communication designs (Ejsing-Duun and Skovbjerg, 2018). During these iterative processes, the students had the role of designers working with different sketching techniques and prototypes (see e.g. Schön, 1983; Twersky and Suwa, 2009). In this way, an essential part of teaching was for students to materialise their ideas and understandings of a wicked problem and the domain of teaching as well as to obtain feedback from peers and teachers when presenting their materialised ideas (Ejsing-Duun and Skovbjerg, 2018).

Like the former study, in this exploratory case study, students were prompted to adopt a pragmatic inquiry approach in their design processes. The students had an end goal of developing games for change, which invites players to relate to a wicked problem and gives players opportunities, awareness and interesting choices in relation to the problem. Unlike our prior research project, the teaching setting for this case study was online, which demanded new ways to create shared spaces for lectures, peer-to-peer presentations, and feedback sessions.

In his book Teaching in a Digital Age, Bates (2017, p.260) emphasises new digital opportunities, which he refers to as 'rich media', media which "differ in terms of their formats, symbols systems, and cultural values". Bates 
claims that online teaching can incorporate a range of different media: text, graphics, audio, video, animation and simulations. According to Bates, the use of different media allows for individualisation and personalisation in learning, suiting learners with different learning styles and needs. Other studies show that teachers' production of videos and video instructions in online settings affect students' engagement and enable a flexible teaching style suiting learners with different needs (e.g. Wells, Barry and Spence, 2012; Guo, Kim and Rubin, 2014). Furthermore, video produced in an informal setting and with the teacher's talking head as a part of the video are more engaging than slides alone or high-fidelity studio recordings (Guo, Kim and Rubin, 2014). This exploratory case study explored both the teachers' and students' use of visualisations and video productions in an online game-based teaching setting and examined their value in these iterative design processes.

The new ways of creating shared online spaces had a focus on combining inquiry practices with visual practices. As an overall perspective, the concept of visual facilitation (Qvist-Sørensen and Baatrup, 2020) was applied to describe and discuss how teachers and students are constantly framing (Goffmann, 1986) the joint online inquiry space through visual representations. Western culture has consistently privileged the spoken and written word as the highest form of intellectual practice and seen visual representations as second-rate illustrations of ideas (Mirzoeff, 2002). In continuation of this perspective, studies argue that for too long, written text has been privileged as a communication form in education, over e.g. visual, kinesthetic and haptic modalities (Bowen and Evans, 2015). By combining inquiry- and visual approaches in this exploratory study, we also want to challenge traditional assumptions about academic practices in higher education.

\section{Method and case description}

The empirical data is primarily based on a 12-week online game-based learning course as part of Nordic Visual Studies and Art Education (hereafter NoVA). NoVA is a two-year master programme, which educates students in contemporary art and visual culture to achieve an understanding of Nordic practices and traditions in art education and visual communication. The aim is to provide students with relevant competencies and didactical interaction skills to work in cross-cultural and international educational environments. Three Nordic universities provide teaching including Aalto University in Helsinki, Konstfack, in Stockholm, and Aalborg University in Copenhagen. During the master programme, each NoVA student enrols in the educational programme at two of these universities. The authors of this paper are teachers of the course analysed. Both are employed at Aalborg University, Copenhagen.

Due to the geographical distance, the NoVA master programme is based on a combination of e-learning, faceto-face meetings and a cross-campus symposium each semester. Thus, the concept of blended learning is the foundation of NoVA. Furthermore, the NoVA master programme relies on problem-based learning (PBL) approaches for students to develop 'criticality', meaning emotional, intellectual and practical independence (Savin-Baden, 2003). Moreover, for PBL, the teachers function as facilitators who organise a learning environment, which involves different activities, e.g. instructions, students' self-directed learning, presentations and feedback sessions (Newman, 2005; Bates, 2017). As part of the NoVA master programme, the use of multimodal approaches, including text, images, audio, and videos are central elements to teaching.

This was the context for developing the online game-based learning course (hereafter 'game course') as a part of the NoVA master programme in autumn 2018. The focus of the game course was for the students to use games and game elements to make a change. Prior to the online course in 2018 , the course was provided in 2016. During the 2016 course, potentials were observed in the students' productions of visualisations as part of their game design and learning processes. One example was a student from 2016 who elaborated on how she and group members used visualisations and cartoon-like drawings when developing and presenting design ideas online across campuses: "These visuals travelled through to the project I did make when gamifying an experience (...) we ended up by using visuals as prompters, e.g. collage and cartoon characters." The student explained how during collaboration, they discussed the potential of using visuals to engage participants in playful game activities. At the same time, she found it beneficial to use visual notetaking in her own learning and reflection processes: "It made the design processes much more tangible for me when I was then applying the theory to the project that we were working on together." These examples show that the student and her group reflected on their use of visual productions, which indicates great potential. Thus, in the second iteration of the course, we included additional guidance and framing of students' visual productions to explore the potential of these methods in joint online inquiry processes. 
As students were asked to adopt the role of game designers, we also consider our role as educators to be designers of teaching (Sørensen and Levinsen, 2018; Ejsing-Duun and Skovbjerg, 2018) when doing educational research. Therefore, the courses from 2016 and 2018 are two iterations in which the teaching has been redesigned based on experiences, and results from this exploratory study will function as inspiration for a new redesign of the course. As mentioned, experiences with the potential of visual productions from 2016 were given even more priority in our didactical considerations for the iteration of the game course in 2018.

Fifteen students attended the game course in 2018, and the data used for analysis included teaching observations, videos of play sessions, students' reflection papers and written and oral evaluations with participants after completion of the course in 2018. Due to the limited data foundation, the purpose of this paper is not to make generalisations about the use of visualisations and video productions in online game-based teaching but to investigate strategies for using visualisations and video productions by both students and teachers to establish a joint online design inquiry. Thus, learning potential and barriers in these online teaching settings were explored.

\section{Theoretical perspectives}

In this section, the design of the game course is concretised and related to online learning at PBL universities as a theoretical foundation to this approach in education. Furthermore, the pedagogical considerations of staging students as game designers, who materialise their inquiry processes through visualisations and video productions, is discussed. This theoretical section concludes with the notion of visual facilitation and framing, which is relevant when describing how the creative online learning environment is framed by both teachers and students.

\subsection{Course content: Critical game design}

In order to provide insight into what the students were taught, this section presents the course content. The purpose of the game course was for students to investigate the game phenomenon in relation to their background in art and to explore how game elements can spur change by engaging players in certain issues. As mentioned, the objective of PBL is for students to develop 'criticality' (Savin-Baden, 2003). This was also a purpose of the game course, and therefore it included critical play design (Flanagan, 2013) as a main theme. As Flanagan (2013, p.6) emphasises, 'Critical play means to create or occupy play environments and activities that represent one or more questions about aspects of human life'. Through this lens, students were encouraged to consider game scenarios that could foster questioning and dialogues about issues normally taken for granted (Flanagan, 2013). In line with the concept that to nurture PBL, teaching must be ill-structured, open and realworld orientated (Savery, 2006), we introduced the course by openly asking: 'Games for change!? Let's explore the possibilities of using games and play for change!'

The course was designed as an iterative design process and joint reflection guided by five different themes: Critical Play - games and activism; Game mechanics; Framing; Place and space; and Participation. In addition to critical play, the game course also introduced 'game mechanics' through the notion of the endogenous meaning of games, where interactive structures in games require players to struggle towards a goal (Costikyan, 2002). Accordingly, students should reflect upon the endogenous meaning of games they played in relation to game mechanics. Game mechanics include rules, goals, challenges, struggles, possibilities of interactions and collaborations between players (Costikyan, 2002). Framing was introduced through 'performing disbelief' (McGonigal, 2003) and 'ambiguity' (Gaver, Beaver and Benford, 2003). Theory about place and space included location-based games (Ejsing-Duun, 2011) and 'games for urban exploration' (Pinder, 2005). Participation included how to engage players in games (Jensen and Lenskjold, 2004). Through these five themes, we aimed to set students as reflective game designers using visualisations and video productions as part of iterative game design processes.

\subsection{Educational design - visualisations and video productions as inquiry approaches}

NoVA students typically have a background in art, design and communication before they join the master programme. Thus, many of the students are familiar with visualisations as part of their work practices; however, the students are in general unfamiliar with theoretical and methodological frameworks for games. Educational studies show that applying visualisation tools and techniques supports design students with an entrance to theoretical fields because it constitutes a familiar way for students to explore and to make sense of situations (see e.g. Bang, Friis and Gelting, 2015). Additionally, a study showed that visualisations support the 
communication of design ideas and collaboration (Twersky and Suwa, 2009). Drawings, pictures and other symbolic tools are important elements of the human repertoire for meaning-making, which also form a joint memory relevant for specific practices (Ivarsson, Linderoth and Säljö, 2009). Pink (2007) explains that researchers can use photographs to document experiences and as concrete reference points in dialogues of experiences afterwards. Thus, we consider the use of visualisations and photos are familiar symbolic tools for students to use when entering the game field as well as when investigating and presenting their design ideas. As mentioned in the introduction, the point of departure for the game course was for the students to adopt a pragmatic approach (Ejsing-Duun and Skovbjerg, 2018) when exploring games for change through design. This approach is based on John Dewey's (1938) concept of inquiry. Dewey proposes that 'doing' is central to understanding how we think and learn by reflecting on our practices (Dewey, 1938). Donald Schön (1983) brings Dewey's thinking into professional practice by creating language that makes it possible for designers to make their knowledge of their own practice visible. By using visualisations, students can externalise tentative and imprecise ideas in sketches (Twerky and Suwa, 2009), leading to a conversation with materials and with peers (Schön, 1983) and thus to refinements in their designs.

Facilitators of education (Newman, 2005) are obligated to create a learning environment for inquiry processes and dialogues. Other educational research has focused on organising learning environments that place the students as learning designers, where the teachers scaffold students' subject-related inquiry, agency, reflection and learning (Sørensen and Levinsen, 2018). In the game course, the students were encouraged to adopt the role of learning designers when designing games with a specific purpose and target group. To scaffold the students' subject-related inquiry (Sørensen and Levinsen, 2018), we organised exercises where students first adopt the role of gamers, experiencing different digital games and location-based games. Second, the students were encouraged to adopt the role of game designers using their own personal game experiences in the collaborative process of developing a game. This approach was inspired by auto-ethnography, where personal experiences are used to understand different cultural phenomena (Ellis, Adams and Borchner, 2011), in this case games.

The game course was taught online. In this context, we explored how students' video productions can expand the time frame of the students design ideas in addition to their more static visualisations and photos. Specifically, in the students' final iteration of their game design exemplifying the game experiences and narrative of the game, still receiving feedback on their design ideas. Based on prior studies, we advocate for video-sketching techniques ( $\varnothing$ rngreen, Henningsen, Gundersen and Hautopp, 2017) where the tentative and unfinished 'sketchy' feeling of the materials (Twersky \& Suwa, 2009) is still in focus. Thus, the learning process of making video productions is central to developing a game design with less focus on making aesthetic video productions ( $\varnothing$ rngreen, et al., 2017). As the focus was students using different media in their inquiry processes, there was also an increasing focus on teachers using visuals and videos when designing online teaching (McKeachie and Svinicki, 2006; Bates, 2017). In order to 'walk the talk', we also engaged in an iterative process exploring the use of visualisations and video productions as a central part of online teaching with an iterative focus on process over product (Guo, Kim and Rubin, 2014; Ørngreen et al, 2017).

\subsection{Visual facilitation: framing and creating the online inquiry space}

Throughout this paper, the ways visualisations and video productions were applied by both teachers and students to create a joint online space for game design inquiry, are presented and discussed. To describe these applications, the notion of visual facilitation is introduced as a way to discuss the dynamic framing of the learning environment.

Visual facilitation stems from the concept of graphic facilitation (Hautopp, 2018; Qvist-Sørensen and Baastrup, 2020) which was formulated in the 1970 s by a group of organisational consultants in California who used visual techniques and tools in groups to find solutions to complex issues (Sibbet, 2019; Qvist-Sørensen and Baastrup, 2020). Initially, the method was inspired by the way designers and architects utilise visualisations and sketching with clients (Sibbet, 2001; 2008). Visual facilitation is a growing practice internationally (e.g. Blijsie, Hamons and Smith, 2019; Sibbet and Wendling, 2019; Qvist-Sørensen and Baastrup, 2020). In 2019, stories were gathered from 50 leading visual facilitators around the world in the book The World of Visual Facilitation (Blijsie, Hamons and Smith, 2019). They are richly cross-disciplinary and practice-based stories but there is limited empirical research in the field, especially related to formal educational settings (Hautopp and $\emptyset$ rngreen, 2018). 
Visual facilitation that "uses visual representations to facilitate interaction in a group of people using structured visual content" (Qvist-Sørensen and Baastrup, 2020, p.20) was included to facilitate the joint online space for game design inquiry. Thus, our purpose was to apply visual facilitation to a formal educational setting: the NoVA game course.

Blijsie, Hamons and Smith (2019) emphasise three main strategies of visual facilitation: 1) Draw live, 2) Use templates and 3) Get a marker in people's hands. In this case study, the focus was not on drawing live as part of the game course as much of the activity was asynchrony. Instead, we created visual templates for the students to act upon, and we encouraged them to draw and to produce visual materials to capture, develop and present their design processes and game design throughout the course. This is in line with the pragmatic approach of the students testing ideas and reflecting upon their practices (Ejsing-Duun and Skovbjerg, 2018). Thus, we argue that the use of visual facilitation strategies can make design processes more explicit and can prompt reflection on the domain of inquiry: here, games as agents for change.

Visual facilitation is originally facilitation with the structured use of pen and paper (Sibbet, 2001; Qvist-Sørensen and Baastrup, 2020), but technology is mentioned as providing "new means to draw, adjust and share our drawings with one another" (Qvist-Sørensen and Baastrup, 2020, p.17). As the NoVA students were widely distributed but needed to share visual products with their peers, digital tools that support visual facilitation in groups were used (Pohl, 2019). Other facilitators suggest that the involvement of participants in drawing and creating videos as part of their online learning processes is crucial (e.g. Lenzo, 2019). Digital tools also enable quick processing and online sharing of visual results (Pohl, 2019), supporting the iterative approach to the game course.

As the concept of visual facilitation in this online learning environment is introduced, different types of analogue and digital visual representations; sketching and visualisations in group work; drawings, video instructions, video recordings of game experiences and video presentations of game design is explored. Thus, the concept of visual facilitation is applied in a formal online setting of higher education where students draw, adjust and share their game design ideas as part of the game course.

As an analytical strategy of the joint inquiry space, the notion of framing should be introduced. According to Goffman (1986), framing is a dynamic and interactional concept for describing participants' activities of defining what is occurring in a specific situation. In line with this perspective, social practices are not predefined or given but are something that participants create and recreate through interactions (Lantz-Andersson, 2009). Applying the concept of framing in the analysis, PBL activities in the game course are viewed as social practices where both teachers and students dynamically create and recreate the online learning environment.

A critical element of how we frame in situations is dependent on earlier experiences and how we relate these experiences to the activity at hand (Goffmann, 1986). Thus, the teachers' constitution of a given course activity is fundamental for what is possible to learn. Framing includes the disposal of resources and tools for the students to engage in (Lantz-Andersson, 2009). Thus, visualisation methods and techniques were introduced to explore how they framed the students' participation and relation to the content matter. According to Goffmann (1986), it is essential to study activities from participants' perspectives to understand how they frame situations. Thus, the emphasis in the analysis of the empirical data was students' reflective utterances and evaluations.

\section{Analysis of the game course}

The analysis is an introspective review of the joint inquiry processes that unfolded during the game course. Based on the initial introduction of the game course, the students were presented to the main task of developing a game for change that they should design through iterative activities during the 12-week course. During the 12week course, five different game theoretical themes were discussed in synchronic online meetings to support the students' asynchronous group work. As mentioned, the course was initially framed by openly asking: 'Games for change!? Let's explore the possibilities of using games and play for change!' The expected learning outcome was for the students to develop a game informed by game theory and refined through game test and peer feedback. After the initial phase, the students were grouped into two-four persons based on common interests, and they began developing their games. Throughout the game course, five groups developed different game designs related to the overall topic of games for change. 
As teachers and facilitators of the online learning environment (Newman, 2005; Qvist-Sørensen and Baastrup, 2020), the teaching of different activities was structured as follows:

- Online meetings: lectures, video instructions, presentations and feedback sessions

- Reflexive exercises

- $\quad$ Students' self-directed design processes and learning in groups

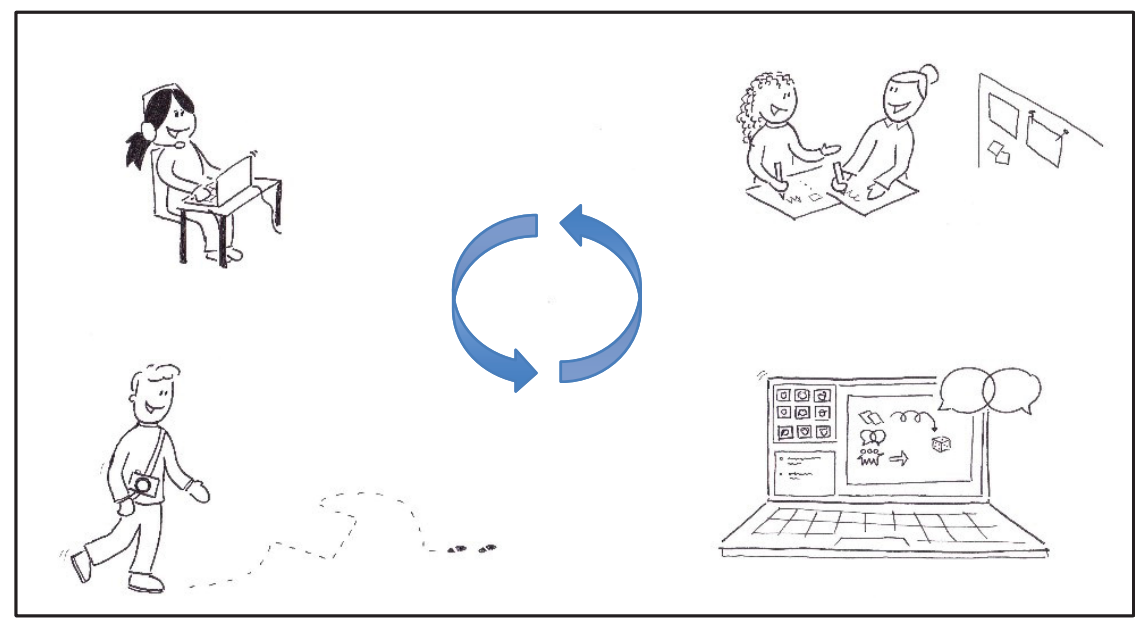

Figure 1: Presentation of the different PBL activities; reflexive exercises, students' group learning and online meetings, etc. (Hautopp, 2019)

The following analysis is organised in relation to the different PBL activities in the course, and the relation between the activities is emphasised. For each activity, examples of students' and teachers' strategies when using visualisations and video productions during the course are discussed.

As we work iteratively with researching educational design, the inquiry process involves producing demonstrable design and changes at the local level and reflecting on the use in other contexts (Barab \& Squire, 2004). Thus, the research approach is justified by the way the educational design work in practice by providing a rich description of context, theory and interventions. In the analysis, we aim to give a rich and visual description of empirical examples discussed in relation the educational design and theories.

\subsection{Online meetings: lectures, video introductions, presentations and feedback sessions}

The course was organised with joint online meetings using the video conference system Adobe Connect. Each meeting focused on a specific theme: 1) Critical Play - games and activism, 2) Understanding games, 3) Framing, 4) Games in place and space and 5) Making an invitation - participation. Initially, online meetings were planned to last for two hours with 20-30 minute lectures of relevant concepts from the specific theme followed by feedback sessions between the students. In parallel with the development of the students' games, we wanted to make space for more joint inquiry and dialogue in the feedback sessions. Thus, the online meetings were redesigned with more time and focus on feedback sessions in smaller groups, placing the lectures in video introductions for students to view between online meetings. According to McKeachie and Svinicki (2006, p.58), lecturing is best used for summarising and adapting material to the interests of a particular group, initially helping students discover key concepts, principles and ideas within a specific topic. In our case, video introductions were used to relate the themes and theoretical game concepts of the week to the students' work designing games. Concrete examples were included for the students to act upon (Dewey, 1938). Thus, the videos were developed between weekly meetings, adapting to the latest online dialogues and feedback sessions and relating new concepts to the designs and discussions with examples tailored to the students' projects. Simple video recording techniques and tools, e.g. screen recordings (Camtasia and Screencast-o-matic) with a teacher's talking head (Guo, Kim and Rubin, 2014) (see figure 2) or PowerPoint recordings in one-take, were used to retain the tentative and imprecise 'sketchy' feeling in the videos ( $\varnothing$ rngreen et al., 2017). 


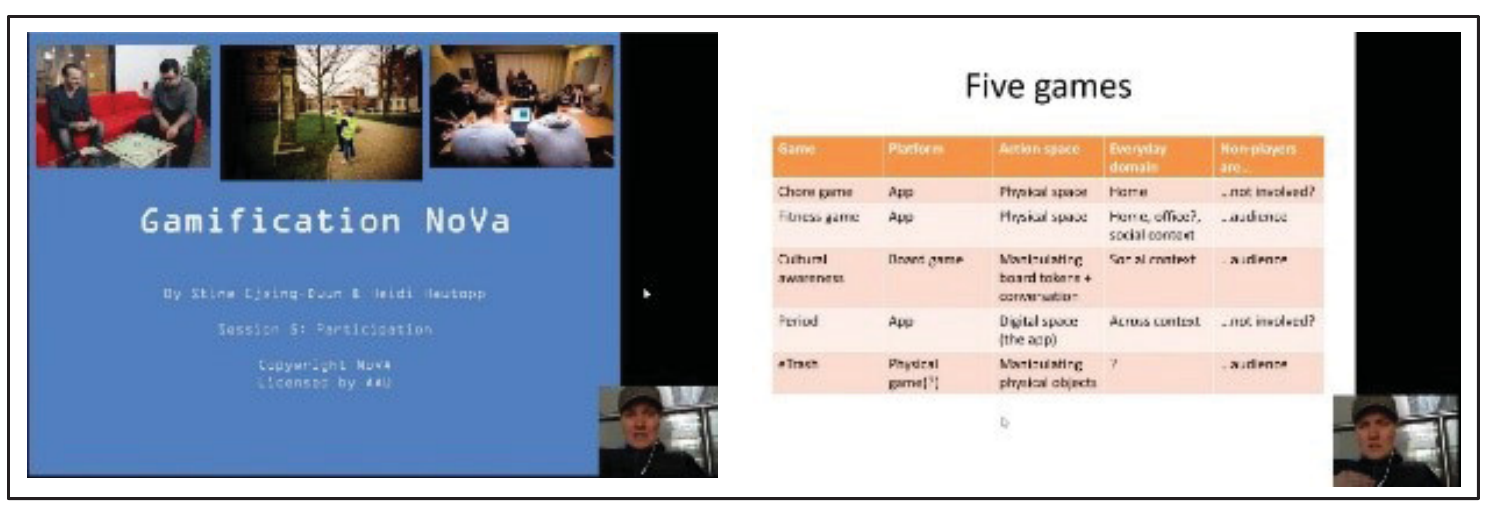

Figure 2: Video instructions with a teacher's talking head in a screen recording with specific feedback on students' game design ideas. The teacher is sitting on a couch and is quite informal

Figure 2 illustrates a video tutorial about the theme 4) Making an invitation - participation. The teacher related the topic by asking the groups 'How are you going to invite people to play your game?', specifically relating the question to each of the five groups and their previous game design ideas. The advantage of this approach to video instructions is that the students generally had experiences with the videos as relevant and meaningful in relation to their design work. In their written evaluations, all students expressed appreciation of the video introductions. This is evident in this student's comment: "I really appreciate that there were videos in advance to see and prepare for an upcoming online lesson. It helped much to concentrate on a specific topic (...), and your feedback about our game design processes was also very helpful. I think these preparation videos with examples (!!) are great." Thus, for this student, the video provided a focal point, which helped in preparing for the next session. This is supported by another student's comment: "The videos were so helpful! It was great to be able to go into the reading knowing a bit about what the context was rather than grappling to understand it. I appreciated the main points and concepts as well, as I was able to get more from the readings with the videos." In this way, the students used the video introductions to frame the readings and design processes as the feedback provides focus and premises for reading and for the design process.

The disadvantage of this approach to making videos is that it can be time-consuming to produce and render the videos. Moreover, the video introductions cannot be reused for the next semester because specific student projects are mentioned in the videos. In the oral evaluation after the course, some students proposed that the videos should be 5-10 minutes instead of 20 minutes, which could be less time-consuming for teachers.

As a central part of the online meetings, students were asked to give a 5-7 minute visual presentation of their current state of game design. Each stage related to the specific game theme of the week; however, online participation requires technical competences. A student elaborated on the experiences of the online feedback sessions: "Of course, this was also not the first online course, so that made a big difference for me having learned and understood the platform and technologies." Thus, an understanding of the different functions of the online platform, e.g. how to share and comment on the visual representation of design ideas, is essential. Other students also appreciated the feedback sessions as highly relevant to their design processes but mentioned online experiences as a factor in the process: "Giving online presentations and being opponents all in all is good for the design processes and in this course it worked perfectly. Personally, it was a bit hard due to a lack of experience in this kind of online learning environment." These findings point to learning potential for the students in the feedback sessions both in the role of presenter and opponent, and at the same time, it is central to have experience with these activities for students to feel comfortable in online learning environments.

Several students mentioned the benefits of feedback for their design processes: "Giving presentations was essential! That way one had to formulate thoughts into a brief space of slides and then somehow share what one was passionate about." Another group acted as opponents to the presentation, giving feedback on the game design using the theories presented for the week. In this way, the students used visualisations to frame the understanding of their game design in relation to specific topics and theoretical perspectives. A student commented on the role of an opponent: "I value peer review. It's good to learn how to communicate both compliments and critical points." We argue that the use of digital tools for quick processing and the elaboration of visual results in a PowerPoint presentation (Pohl, 2019) made the students' game designs explicit and applicable for joint inquiry in the feedback sessions. 


\subsection{Reflexive exercises}

To encourage students to activate relevant prior knowledge of games and art (Goffmann, 1986; Newmann, 2005) as well as to engage them in new game experiences, we structured reflexive exercises between the online meetings for students to act as gamers as well as game designers (Levinsen and Sørensen, 2018). The reflexive exercises targeted the different themes of the online meetings and required the students to take an autoethnographic approach with a focus on the personal experience of playing the game (Ellis, Bochner and Adams, 2011). Examples of activities are: 1) Present game experiences and post questions for debate in an online forum; 2) Make a video screen recording playing a self-chosen game in relation to game mechanics and definition of games; and 3) Make a dot.walk in relation to the theme Games in place and space as an example of a locationbased game. As part of the reflexive exercises, the students were asked to write a two-page reflection paper for each online meeting reflecting both the exercise, the game theory and the group work on developing games. The individual exercises were a supplement to the students' group work, and the purpose was for the students to embed the game concepts in relation to different activities. Through these exercises, they strengthened their entrance into the game field.

One reflexive exercise was a dot.walk (Medienkunstnetz, n.d.) for which the purpose is to be guided in a city by simple codes and instructions (turn left 1st street, turn right second street, turn left third street). The walk was set to take 10 minutes, and the students were asked to document their walk by taking five photos to reflect on their experiences and to subsequently adjust the instructions for the game to redesign it. This was reported in a two-page reflection paper. The purpose of the dot.walk was for the students to try a location-based game (Ejsing-Duun, 2011) and to experience how simple rules can produce new actions and playful activities in a wellknown area. In this exercise, the game structure is framing a behaviour, and the instructions framed the students' meta-reflections on the framing. The act of taking photos is a framing in itself because the student taking the photo focuses on what is within the frame of the photo, leaving something out.

A central part of PBL is facilitating self-directed learning (Newman, 2005); however, this can be difficult when students are situated across campuses. In the first course in 2016, the presentations of the dot.walk were not specifically framed, making it difficult for students to use their experiences for discussions and as materials for design. To improve this, we made a visual template of a dot.walk created as a PowerPoint recording using sketchy drawings, photos and a voice-over reflecting on their own walk experiences to instruct and to inspire students (see figure 3).

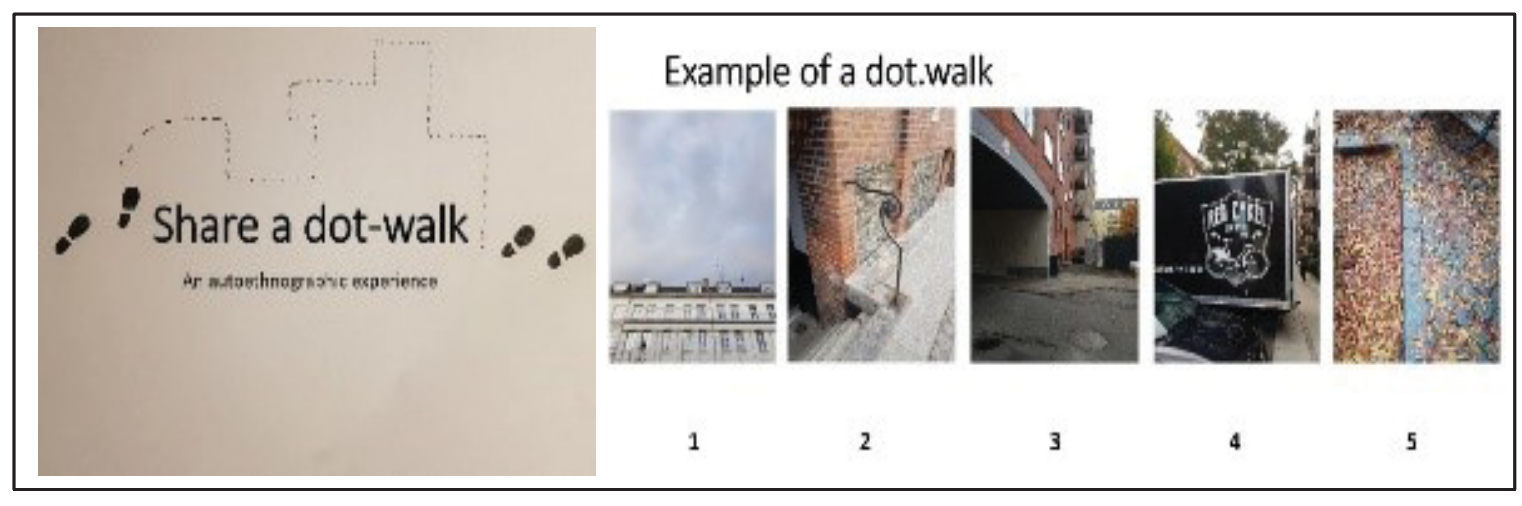

Figure 3: Examples from the teachers' visual template of a dot.walk

This template was intended to frame the exercise so that students could perform it on their own and share it within their groups and during the online meeting. In this exercise, the visualisations provided students with a tangible memory of their walk and made it possible for the group to facilitate a discussion about their experiences.

In addition to taking photos during the dot.walk, some students decided to draw a map of their walks or visualised the route in a Google map (see figure 4). Thus, students used different visual representations to facilitate an understanding of their walks for fellow students and teachers. 


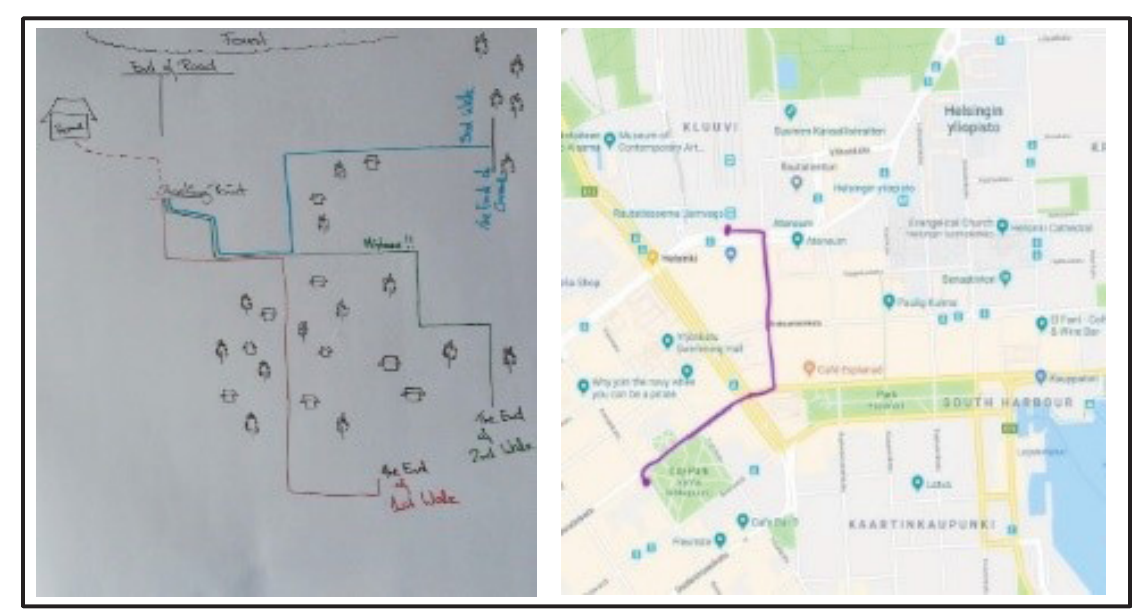

Figure 4: Students' drawings of walks and visualisations of a route in Google maps

The student drawing the map of her walks meta-reflected upon the importance of the 'framing of games' when she almost went to dead-end road in her second dot.walk: "This experience only emphasises the importance of game design and why the framing of the game is a significant part. As for players, this experience emphasises the importance of following the rules if we want to engage with the game". From a pragmatic perspective, this student theoretically reflected upon her own game experiences with location-based game by noting how framing and rules are significant for players' engagement.

In his first dot.walk, another student stumbled upon a rear-view mirror on the roadside (see figure 5a). He described the normal use of these types of mirrors as well as how they could function as a creative and playful way to challenge the game experience: "This mirror is used for cars to see whether there is traffic but it is a nice feature which can alter or show you another dimension of where you are about to walk.".

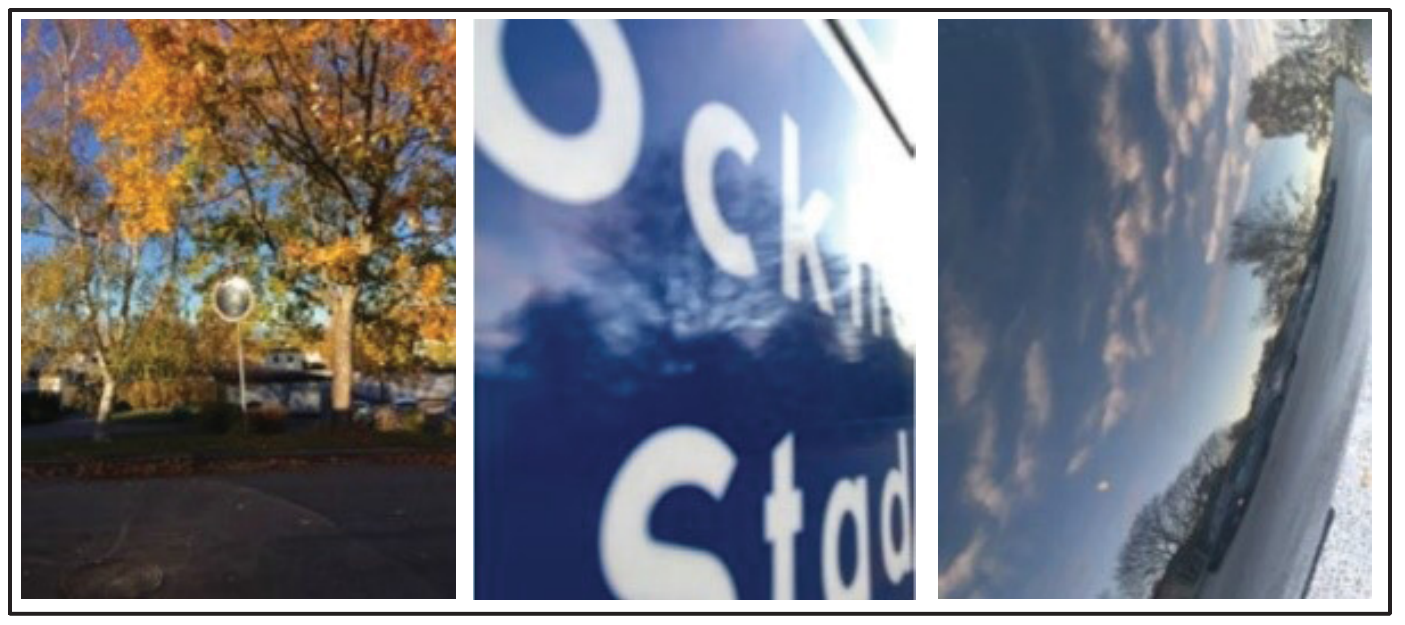

Figure 5: Photos from a student's dot.walk: a photo of a rear-view mirror on the roadside (5a) and two photos of 'reflecting things' (5b-c)

On the second dot.walk, he adjusted the codes and instructions inspired by his previous experience: "New code: Only take photographs in reflecting things. That way, you can create the feeling of another dimension." (see figure $5 b-c)$. After the second walk, the student reflected upon this way of framing photos focusing on reflecting objects: "The new code made it much more playful to observe the area. It was also a challenge finding the reflecting objects everywhere, and it brought out the fact that more things than I expected do have a reflection of landscape! " In this meta-reflection, the student argued based on own experiences that "making a code or guidelines is good, altering the ordinary is even more important. So, the twist is what makes the walk exciting". In addition to the two-page reflection paper, the students also shared their dot.walk experiences scaffolded by the teachers during the next online meeting. Among others, it was discussed that 'altering the ordinary' is a crucial game mechanic when framing critical design (Flanagan, 2013) in games for change. 
In these self-directed reflexive exercises, students used visualisations to engage with the topics presented, and a dialogue with their own experiences invited their peers into the dialogue. As such, the visualisations enabled and framed academic discussions and inquiry across space and time.

\subsection{Students self-directed design processes and learning in groups}

In retrospect, the individual reflection exercises also functioned as shared inquiry spaces for the students to combine their interests in art and photographs to design games. Thus, the exercises also lay a foundation for the students' self-directed learning in groups. For example, a walk in the subway in Stockholm taking photos was used as an inspiration for a game for change with a focus on women's periods. In the subway, the students took photographs of graphic artist Liv Strömquist's enlarged visualisations of women having their periods, some of them entitled: "I'm alright (I'm only bleeding)." This exhibition has created public debate (Hunt, 2017) and in their presentations, the students used their pictures to make a critical stand in line with the artist regarding taboos related to women's periods. It can be argued that the students used this inspirational walk in the subway to foster ideas of how to question normative assumptions of women's periods through a critical game design (Flanagan, 2013). During their game development, the students made their own visualisations inspired by the originals (see figure 5), which they incorporated as a part of their game design.

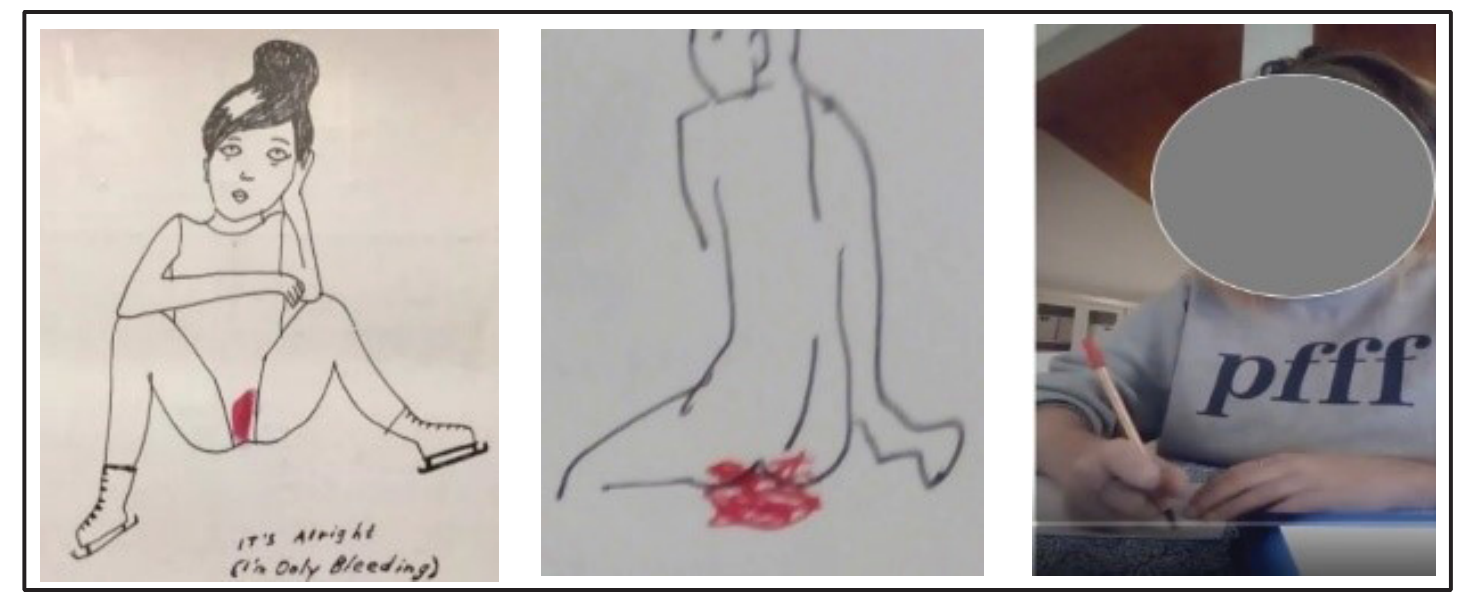

Figure 6: Visualisation by Liv Strömquist, a student visualisation and a play session from video productions

In their final presentation of the 'Period game', the students produced a video showing a player engaging with the game, which was designed as an app that provides scenarios exemplifying issues related to menstruation. This game concept was inspired by Playspent.org, which is a game that one group member played in the first auto-ethnographic exercise of playing a game to reflect upon game mechanics and experiences. The app was created as a paper prototype, and one student acted as the player in the video, discussing her choices (see figure 6) when she encountered challenging choices in the game (Costikyan, 2002). The player assumed the role of a fictive character, a 16-year-old British female from a low socio-economic background. Related to facts that British teenagers sometimes cannot afford menstrual products due to high costs, the character is placed within dilemmas, such as: "Your period had started this Tuesday morning, but your parents did not have enough money this month for period pads and are too tight in their budget to give you some for the upcoming days. School starts in one hour. What do you do?" Throughout the game, players must make decisions in relation to economic, health and personal issues related to menstruation. The video production made the struggle in the game visible (Costikyan, 2002), which was used as a reference point for the students to discuss different perspectives of women's periods during the feedback session (Flanagan, 2013; and teaching observations).

Other students were inspired by the different ways to complete the reflexive exercise of making a video recording of a self-chosen game. One student chose to record herself playing a digital game about cultural differences, and she reflected upon how games can focus players' attention on their own stereotyping of other groups. Together with three other students, she formed a group, and they began an inquiry process to explore how a game can foster inviting dialogues and interactions based on cultural issues (Flanagan, 2013; Costikyan, 2002). In the beginning of their design process, the students were keen on making an app as their final game design, but after their second round of peer feedback, they changed their idea. The students wanted to target social aspects of cultural sharing, and the choice of an app as the playground was questioned by fellow students 
regarding whether it was the right solution for the purpose. Throughout the course, students were focused on the fact that the game should be playable and in line with their purpose so that it could be tested. This framing was important because they assessed their ideas and adjusted the design during the course. Based on feedback, the students redesigned their initial idea into a board game, which embraced the social aspects of the game to a greater extent. In their final video presentation of their game 'Cultural awareness', the students showed the game play by exemplifying different game situations. The students showed the play situations by starting with a zoom on the specific game card (see figure 7), which invited participants into a dialogue about cultural items and dilemmas (Flanagan, 2013).

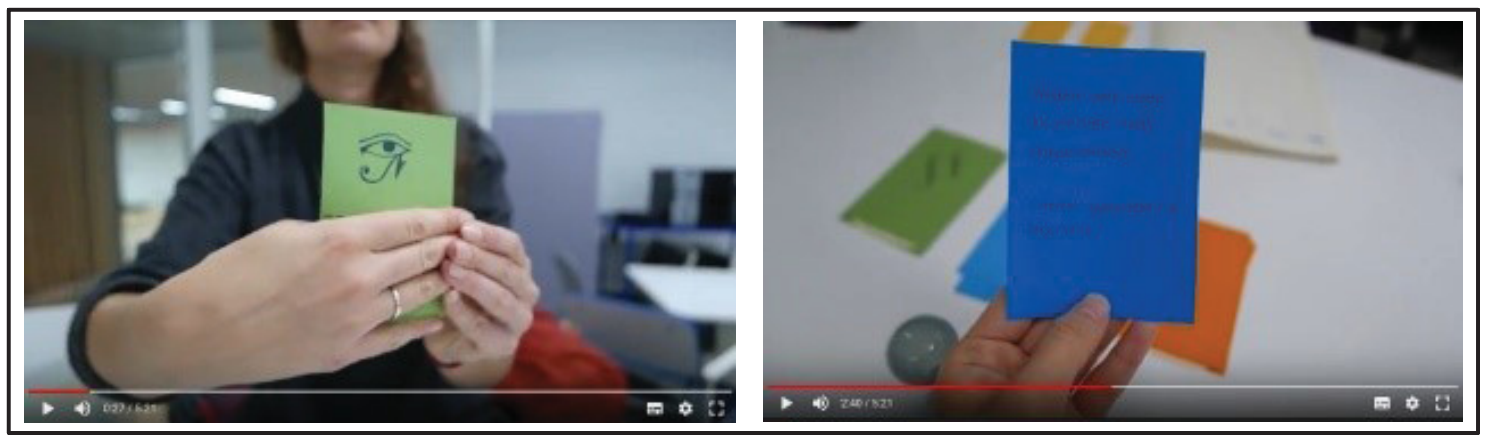

Figure 7: Play situations starting with a zoom on specific game cards

Green game cards represented different cultural symbols, and players wrote down their interpretations and afterwards explained their motives for their guesses in plenum. Subsequently, the players negotiated the individual score of one to three points in relation to their answers. In case of disagreement, the presenter of the question has the final word. In a new game situation, one player draws a blue card from the pile and reads aloud: "Western poet creates his pen name using a Chinese character. Cultural appropriation or inspiration?" The players then decide for themselves how they will characterise the action of the poet and choose between cultural appropriation or inspiration while selecting a yellow card representing their choice. Afterwards, players reveal their choices by turning yellow cards, which leads to a conversation about the background of their choices. In their final video productions, the game narrative and endogenous meaning (Costikyan, 2002) of the cultural dilemmas as context-dependent and negotiable became visible in the students' game structure focusing on dialogues and joint negotiations about scores.

As an overall analytical perspective, the students used visual facilitation techniques as they engaged fellow students and teachers in their game narratives through different visual representations, such as visualisations and video productions, making their game designs relatable and discussable in an online setting.

\section{Discussion}

The analysis has shown different examples of how teachers and students use visualisations and video productions to facilitate and to create a shared online inquiry space, some students with more game and online experiences than others. Some students expressed that both before and after the game course, they were not particularly passionate about games. Despite the lack of interest in games, several expressed that they could find a personal focus in the course, e.g. a political interest in the game culture or an interest in the exploratory approaches and theory presented during the course: "The texts were many and very interesting and I was amazed by the text on auto-ethnography. There I saw that the theory was not only about games but also about the research approach of ethnographers exploring a certain field and culture within academia approach." The fact that we combined the academic inquiry approaches with visualisations and video productions as methods familiar to the students (Bang, Friis \& Gelting, 2015) can be an explanation of the appreciation of the course despite the lack of interest in games. As another student expressed, her understanding of games was wider after the course which she related to her profession as an art teacher: "In artistic creativity - when designing workshops or learning class, now I could include different approaches (...) Also when thinking about community based art projects, I will definitely remember about games as part of activism". This quote exemplifies, how games for changes are not just about the specific games, but also about the approaches embedded in the game design when inviting participants to play and to take an active part in critical issues. As this was an exploratory case study of one game course, the student evaluations revolved around the specific course. A long-term 
perspective on the implications of combining academic inquiry approaches, visual facilitation techniques, and game theory in higher education, needs further research.

As mentioned, a central point of the game course was for students to take a pragmatic approach (Ejsing-Duun and Skovbjerg, 2018) to explore games for change through design based on John Dewey's (1938) concept of inquiry. As teachers, we also adopted this explorative approach to develop teaching materials, e.g. visual templates and video instructions based on the dialogue with students from the previous online meeting. Thus, this adaptable way of preparing our teaching had the benefit of students' appreciation of specific weekly feedback in video instructions. On the other hand, when asked about the overall experience of the game course, a student mentioned: "I wouldn't really change anything. I think that the assignments supported the course and theory and gave the students a good feel of all the different aspects of games. The only thing I would change is the time frames; I would make sure that all the assignments were up weeks before they were due". An overview of the schedule and all assignments from the beginning of a course could be useful, but it should be up for discussion whether this is doable and suitable when educators have the role of designers of teaching (Sørensen and Levinsen, 2018; Ejsing-Duun and Skovbjerg, 2018).

The analysis has shown examples on how students used visualisations and video productions in their reflective exercises, group work, and to materialize their understanding of course specific themes. The students' visual materials was used in presentations in the online feedback sessions which made game experiences explicit and reference points for joint discussions. Online teaching can be viewed as a social practice where both teachers and students dynamically create and recreate the online learning environment (Goffmann, 1986). In this context, visual facilitation in form of teachers' and students' visualisations, visual templates and video productions was developed as part of the asynchronic course work. Furthermore, in the synchronic online sessions, the students' visual productions were used as representations of group work and game designs driving the feedback and discussion in plenary. Thus, a visual social practice in the inquiry processes was created and recreated throughout the different PBL activities. However, as Blijsie, Hamons and Smith (2019) emphasize, one of the main strategies of visual facilitation is to draw live in order to support collective thinking in situ. This strategy of live drawing in plenary should be elaborated in further studies, as potentials for creating more in situ drawing sessions could affect the oral feedback discussions, participation and learning. In this perspective, the relation between joint inquiry processes of inventing a game and the act of drawing could be explored as an interaction between student groups and teachers in online settings. This might also call for teachers to frame the online meetings even more student driven (Newman, 2005), making space for students to facilitate the PBL activities and host the online sessions. Thus, the students could be further involved in framing relations between e.g. art and games.

As we discuss analytical results, a limitation of studying own teaching can be our joint roles as both teachers and researchers. In educational design, researchers are not simply observing interactions but are actually "causing" the very same interactions they are making claims about (Barab \& Squire, 2004). Therefore, it has been essential to study activities from students' perspectives to understand how they framed the teaching situations (Goffmann, 1986). Moreover, in educational design research manifold contexts are conditions, which makes it difficult to replicate others' findings (Hoadley, 2002). In educational design, the goal is therefore not to sterilize naturalistic teaching contexts eliminating all confounding variables, e.g. own involvement, so the generated result is more valid and reliable. Instead, the challenge is to develop flexibly adaptive design interventions and results that remain useful even when applied to new local contexts (Barab \& Squire, 2004). By the rich and visual descriptions of PBL activities, student work and reflective evaluations in the analysis, the exploratory case study can function as inspiration for applying similar approaches to new local contexts in higher education.

\section{Conclusion}

This paper discusses empirical examples of the establishment of shared online spaces for joint design inquiry in the context of games for change across cultural and professional barriers. The study focused on incorporating teachers' and students' use of visual facilitation and representations, e.g. visualisations and video productions, as central parts of creating and framing shared online spaces across the three university campuses. The analysis of PBL activities showed that teachers' video introductions relating theoretical game concepts to the students' group work supported their entrance into the game field as well as their design processes. Thus, the pragmatic abductive approach which starts in own experiences created space for students' more theoretical readings and reflections in relation to the course content of designing games for change. The way to balance feedback-related 
video introductions and teachers' time for preparation is identified as a relevant issue for further exploration in online game-based teaching. Students' different strategies of using visualisations and video productions in reflexive exercises and design processes made the game experiences and narratives visible for students across campuses, which enabled further discussions during the feedback sessions and supported the joint inquiry processes. The combination of inquiry approaches, critical game theory and design processes combined with students' visualisations and video productions has interesting connections for bridging gaps between professions, e.g. in art and games. This combination was used to visually facilitate the online joint inquiry space and should be further explored in research studies. For example, the use of live drawing in the online feedback sessions is identified as a relevant focus for further studies in order to explore how these approaches might enhance the joint inquiry processes.

As the aim of the study was to investigate strategies for using visualisations and video productions by both students and teachers to establish a joint online design inquiry, the paper reflects this aim by making the teaching and research process visual through concrete examples in the analysis. Thus, the exploratory case study privilege visual modalities, which are requested in academic practices (see e.g. Mirzoeff, 2002; Bowen and Evans, 2015) and can function as inspiration for applying similar approaches to new local contexts in higher education.

\section{Acknowledgement:}

We would like to thank the NoVA master students (2018-2020) for creative and engaging participation in the online game course and evaluation. Likewise, we would like to thank NoVA community for constructive feedback.

\section{References}

Bang, A. L., Friis, S. A., and Gelting, A. G., 2015. Designerly Ways to Theoretical Insight: Visualisation as a means to explore, discuss and understand design theory. Design and Technology Education: An International Journal, 20(1).pp 8-17

Barab, S. and Squire, K., 2004. Design-Based Research: Putting a Stake in the Ground, Journal of the Learning Sciences, 13:1, 1-14, DOI: 10.1207/s15327809jIs1301_1

Bates, T., 2017. Teaching in the digital age: Guidelines for designing teaching and learning. Available through: https://opentextbc.ca/teachinginadigitalage/ (Accessed: 29 June 2020)

Blijsie, J., Hamons, T. and Smith, R. S. ed., 2019. The world of visual facilitation. Unlock your power to connect people \& ideas. Holland: The Visual Connection Publishers.

Bowen, T. and Evans, M.M., 2015. What Does Knowledge Look Like? Drawing as a Means of Knowledge Representation and Knowledge Construction. Education for Information, 31, pp: 53-72. DOI: 10.3233/EFI-150947

Costikyan, G., 2002. I have no words \& I must design: toward a critical vocabulary for games. In: Proceedings of the computer games and digital cultures conference. Tampere: Finland, June 6-8

Ellis, C., Adams, T. E. and Bochner, A. P., 2011. Autoethnography: An Overview. Forum: Qualitative Social Research, 12(1), pp. 273-290.

Dewey, J., 1938. Logic: The Theory of Inquiry. New York: Holt, Rinehardt and Winston.

Ejsing-Duun, S., 2011. Location-based games: from screen to street. PhD dissertation, Danish School of Education

Ejsing-Duun, S. and Skovbjerg, H. M., 2018. Design as a Mode of Inquiry in Design Pedagogy and Design Thinking. The International Journal of Art \& Design, 38 (2), 445-460. https://doi.org/10.1111/jade.12214

Gaver, W. W., Beaver, J. and Benford, S., 2003. Ambiguity as a resource for design. In: Proceedings of the SIGCHI conference on Human factors in computing systems. ACM, 2003.

Goffmann, E., 1986. Frame analysis: An essay on the organization of experience. Boston, MA: Northeastern University Press.

Guo, P. J., Kim, J. and Rubin, J., 2014. How Video Production Affects Student Engagement: An Empirical Study of MOOC Videos. In Proceedings of the SIGCHI Conference (10 pages)

Hautopp, H., 2018. Fieldwork at EuViz 2018: European Conference for Visual Practitioners - in relation to PhD project, Rungsted, Denmark. Available through: https://vbn.aau.dk/da/projects/fieldwork-at-euviz-2018-europeanconference-for-visual-practition (Accessed: 29 June 2020)

Hautopp, H. and Ørngreen, R., 2018. A Review of Graphic Facilitation in Organizational and Educational Contexts. Designs for Learning, 10(1), pp. 53-62. https://doi.org/10.16993/dfl.97

Hautopp, H., 2019. Presentation of ECEL conference paper: The use of Visualisations and Video productions in Online Game Based Learning. Available through: https://vbn.aau.dk/da/activities/presentation-of-ecel-conference-paperthe-use-of-visualisations-a (Accessed: 29 June 2020)

Hoadley, C. P., 2002. Creating context: Design-based research in creating and understanding CSCL. Proceedings of Computer Support for Cooperative Learning, Boulder, CO. (9 pages)

Hunt, E., 2017. Enjoy menstruation, even on the subway: Stockholm art sparks row. The Guardian, International Addition. Available through: https://www.theguardian.com/cities/2017/nov/02/enjoy-menstruation-subway-stockholm-artrow-liv-stromquist (Accessed: 29 June 2020) 
Ivarsson, J., Linderoth, J. and Säljö, R., 2009. Representations in practices. A sociocultural approach to multimodality in reasoning. In C. Jewit ed.: The Routledge Handbook of Multimodal Analysis. Routledge, pp. 201-212.

Jensen, R. and Lenskjold, T., 2004. Designing for social friction: Exploring ubiquitous computing as means of cultural interventions in urban space. In: Web Proceedings of CADE'04 (2004).

Lantz-Andersson, A., 2009. Framing in Educational Practices. Learning Activities, Digital Technology and the Logic of Situated Action. PhD dissertation. Göteburgs Universitet.

Lenzo, A., 2019. Connection, Collaboration, Creativity: Using Visuals for Online Engagement In: J. Blijsie, T. Hamons, and R. S. Smith, ed. The world of visual facilitation. Unlock your power to connect people \& ideas. (pp. 405-413) Holland: The Visual Connection Publishers.

McGonigal, J., 2003. A real little game: The performance of belief in pervasive play. Level Up Conference Proceedings at gameconference.org

McKeachie,W. and Svinicki, M. (2006) McKeachie's Teaching Tips: Strategies, Research and Theory for College and University Teachers Boston/New York: Houghton Mifflin.

Medienkunstnetz, n.d. WALK. Available through: http://www.medienkunstnetz.de/works/dot-walk/ Accessed: 29 June 2020

Mirzoeff, N., 2002. The Visual Culture Reader. 2nd ed. London and New York: Routlegde Taylor and Francis Group

Newmann, M., 2005. Problem Based learning: An introduction and overview of the key features of the approach. Journal of Veterinary Medical Education, pp 12-20.

Pinder, D., 2005. Arts of urban exploration. Cultural Geographies, 12(4), pp. 383-411.

Pink, S., 2007. Doing Visual Ethnography. 2nd ed. London: SAGE Publications.

Pohl, H., 2019. The Case for Digital FacilitationIn: J. Blijsie, T. Hamons, and R. S. Smith, ed. The world of visual facilitation. Unlock your power to connect people \& ideas. (pp. 381-387) Holland: The Visual Connection Publishers.

Qvist-Sørensen, O. and Baastrup, L., 2020. Visual Collaboration. A Powerful Toolkit for Improving Meetings, Projects, and Processes. New Jersey: John Wiley \& Sons, Inc.

Savery, J. R., 2006. Overview of Problem-based learning: Definitions and distinctions. Interdisciplinary Journal of ProblemBased Learning, 1(1), pp. 9-20.

Savin-Baden, M., 2003. Facilitating problem-based learning - Illuminating perspectives. Philadelphia, PA: McGraw - Hill Education.

Schön, D. A., 1983. The reflective practitioner: How professionals think in action. London, UK: Temple.

Sibbet, D., 2001. A graphic facilitation retrospective. In: Proceedings of the International Association of Facilitators: The Art and Mastery of Facilitation - Navigating the Future IAF Conference, 2001, May 16-20. Minnesota. DOI: https://doi. org/10.1080/00405840801992306.

Sibbet, D., 2019. Foreword In: J. Blijsie, T. Hamons, and R. S. Smith, ed. The world of visual facilitation. Unlock your power to connect people \& ideas. (p. XVII-XIX) Holland: The Visual Connection Publishers.

Sibbet, D. and Wendling, G., 2019. Visual consulting. Designing and leading change. New Jersey: John Wiley \& Sons, Inc.

Sørensen, B. H. and Levinsen, K., 2018. Teachers' Learning Design Practice for Students as Learning Designers. In: Proceedings of the 6th International Conference on Designs for Learning 23-25 maj 2018, Bergen Norway (26 pages)

Twersky, B. and Suwa, M., 2009. Thinking with sketches In: A. Markmann and K. Wood, eds. Tools for innovation. Oxford: Oxford Scholarship Online.

Wells, J., Barry, R. M. and Spence, A., 2012. Using video tutorials as a carrot-and-stick approach to learning. IEEE Transactions on Education, 55(4), pp. 453-458.

$\emptyset$ rngreen, R., Henningsen, B., Gundersen, P. B. and Hautopp, H., 2017. The Learning Potential of Video Sketching. In: D. A. Mesquita and D. P. Peres eds. Proceedings of the 16th European Conference on e-learning ECEL 2017: ISCAP Porto, Portugal, 26-27 October 2017 (pp. 422-430). 